E S T U D I O S 


\title{
EL PROBLEMA DEL INTELECTUALISMO VOLUNTARISMO EN LA CONGEPGION DE LA LEY ETERNA
}

\author{
Ramón Mací́ Manso \\ Profesor de Filosofia del Derecho \\ Universidad de Ovicdo
}

S U A A R I O

Introducción. I. Diversas concepciones y problemas de las normas. II. Crítica de las concepciones. III. Dios creador y legislador. IV. Concepciones de la norma y ley eterna. V. Problemas de la definición de San Agustín y teoría de Duns Scoto. VI. Conclusiones.

San Agustín dio, entre otras, una definición de la ley eterna muy conocida en la posteridad. La ley eterna, según el obispo de Hipona, puede definirse como la "ratio vel voluntas Dei, ordinem naturalem conservare iubens perturbari vetans"1.

Muchas veces se ha creído que esta definición encierra los enunciados de la concepción intelectualista y de la voluntarista de la ley cterna y que el enunciado completo de cada una de aquellas se puede obtener por el simple desglose de la definición. Así la concepción intelectualista de la ley eterna vendria expresado por, "la razón divina que manda conservar el orden natural y prohibe perturbarlo" y la concepción voluntarista por, "la voluntad divina que manda conservar el orden natural y prohíbe perturbarlo". Sin embargo esta créncia es errónea, al menos en parte, como mostraremos posteriormente”.

'Contra Faustum, xxiI, 27. Vid. otras definiciones en De libero arbitrio, 1. 6: De Trinitate, $\mathrm{xy}, 14$.

"IIans Wclzel, por ejemplo, consiclera que csta definición de San Agustín conticuc tanto la posibilidad de und interpretación intelectualista -que stras veces llawa idealista- como la de un entendimiento voluntarista 
Por otro lado esta definición de la ley eterna sin duda puede suscitar el problema de si es la razón o bien la voluntad de Dios-ratio vel voluntas Dei-la que manda conservar tal orden. En base a esta definición cabe preguntarse, pues, si San Agustín sustenta en definitiva la concepción intelectualista o la voluntarista de la ley eterna, suponiendo que estas concepciones vengan expresadas por las fórmulas que hemos separado. Muchos comentaristas se han planteado así el problema sin hacer reparo alguno $y$, para solucionarlo han acudido, como es lógico, a otros pasajes del pensamiento agustiniano.

Convienc indicar ya desde ahora -posteriormente trataremos de aclararlo- que el segundo enunciado no expresa en modo alguno un entendimiento voluntarista de la ley eterna y por eso, afirmar que la voluntad divina es la que manda conservar el orden natural, no implica defender una postura voluntarista respecto de esta ley.

Se pueden sacar dos consecuencias de la aseveración que acabamos de hacer. Una primera que sólo nos interesa en forma marginal porque no afecta sustancialmente al desarrollo de este trabajo, es que de aquella definición no se puede obtener razón suficiente para plantear el problema de si San Agustín mantiene o no una concepción voluntarista de la ley eterna. Quizás podrá plantearse a propósito de otros pasajes de sus obras, pero de éste precisamente, no.

Sin embargo hay que reconocer que tal definición ha servido de estimulo para tomar conciencia del problema de la razón y de la voluntad en la estructura de la ley y, desde esta base, es fácil llegar a desembocar en la verdadera cuestión del intelectualismo-voluntarismo.

Santo Tomás, como es bien sabido, empieza el tratado de la ley cuestionándose si ésta es algo que procede de la razón del legislador. Los teólogos juristas españoles de la escolástica replantearon el mismo problema siguiendo las huellas del Doctor Angélico, ampliando a veces

-que también denomina existencialista- de esta ley, pucs entiende que deja sin resolver si el orden de la creación es producto de la razón o de la voluntad. Cfr. Derecho natural y justicia material. Aguilar. Madrid. 1957, 65-66. A. F. Utz afirma que si bien no cabe duda de Ia estructura intelectualista de la ley eterna en San Agustín, con todo en esta definición no se puede excluir la consideración voluntarista y puede inducir al cquívoco de interpretarla "como si la ley eterna fuera la fuerza activa de la decisión de la voluntad divina sin atender al aspecto intelectual". Cfr. Etica Social. Herder. Barcelona. 1965, If. 86 . 
con el estudio del papel desempeñado por la voluntad y algunos a propósito de este problema, comentaron explícitamente la definición agustiniana que hemos transcrito. Por otro lado la escuela franciscana, en general, llegó a estas mismas cuestiones a partir de otros derroteros que llevaban a plantear seriamente la cuestión teológica del voluntarismo divino y sus implicaciones en la ley eterna.

En segundo lugar se deduce de la afirmación antes sentada - y esto es básico para situar el enfoque de este estudio- que la definición de la ley eterna dada por San Agustín, no puede servir adecuadamente, ni siquiera como punto de partida para saber lo que significa la concepción intelectualista y voluntarista en referencia a la ley eterna.

Después de estas observaciones, podemos ya manifestar el propósito que perseguimos en este trabajo. No intentaremos realizar un recorrido histórico de las interpretaciones surgidas en torno a la fórmula agustiniana, ni tampoco registrar las verdaderas posiciones intelectualistas o voluntaristas que han ido surgiendo en cuanto al entendimiento de la ley eterna. Queremos estudiar algo previo: si es posible, o no, desde una posición intelectualista o voluntarista de la ley eterna, y si éstas son las únicas posibles o si caben además otras. En definitiva, plantearemos como problema la posibilidad de una concepción intelectualista y voluntarista en el plano de la ley eterna. No partiremos, pues, dogmáticamente admitiendo que existe la posibilidad de tales interpretaciones de la ley eterna, sino que esto es precisamente parte de lo que debemos investigar, discutiendo criticamente estas y otras posibilidades.

\author{
I. DIVERAS CONCERCIONES Y \\ PROBLEMAS DE IAS NORMAS
}

Uno de los objetivos finales fijados, es llegar a saber si es posible mantener una concepción intelectualista y voluntarista de la ley eterna. Para ello necesitamos saber muy precisamente qué es o representa la concepción intelectualista y voluntarista de esta ley.

Por de pronto ha quedado descartada la definición agustiniana como pauta para llegar a delimitar tales conceptos. El intelectualismo y el voluntarismo en la concepción de la ley eterna - si es que son posibles tales concepciones- son un caso particular de la concepción intelectualista y voluntarista de la norma en general. El punto de 
partida, por ello, ha de consistir en esclarecer primero qué sc ha entcndido o ha de entenderse por concepción intelectualista y voluntarista de una norma. Una vez aclarado este punto es ya posible pasar al plano de la ley eterna, es decir, entonces será el momento de considerar críticamente si tales nociones son o no aplicables a la ley eternit.

Ahora bien, ocurre que el intelectualismo y el voluntarismo son dos posturas posibles y extremas, pero no las únicas, pues caben otras complementarias bajo el mismo ángulo de visión. Es conveniente considerarlas todas y conjuntamente para obtener el marco teórico completo. Esto permitirá luego por medio de los diferentes esquemas, verificar todas las posibilidades e imposibilidades de concepción de la ley eterna, desde un determinado ángulo.

En primer lugar definiremos todas las posibles concepciones teóricas de las normas que se pueden obtener al enfocarlas desde el ángulo preciso de consideración del papel que juega la razón y la voluntad en su constitución y génesis. $\mathrm{Y}$ en segundo lugar analizaremos sucesivamente la posibilidad o imposibilidad de aplicar cada uno de los esquemas teóricos a la ley eterna, o más exactamente, a lo que comúnmente se entiende por ley eterna dentro de la concepción escoIástica y neoescolástica del mundo.

Al reflexionar sobre la génesis y entidad de las normas reguladoras de conductas humanas, inmediatamente se encuentran una serie de incógnitas, que incitan a plantear formalmente varios problemas sobre distintos aspectos de la norma o relacionados con ella. Tales son brevemente enunciados: quién puede dar una norma y a quién puede darse; por qué y para qué puede crearse; cuándo y cómo puede constituirse; cuál es su modo específico de ser y qué o cuál puede ser el contenido de una norma.

La pregunta “¿quién puede crear una norma?”, plantea explícitamente el problema de la competencia del legislador y la pregunta ¿a quién puede dirigirse o imponerse?", constituye el problema de los destinatarios de las normas. Las preguntas sobre el por qué y el para qué de las normas, formulan los problemas de la motivación y finalidad de las mismas. El cuándo afecta a la cuestión de la promulgación y duración de las normas, esto es, plantea el problema del principios y fin de su vigencia. El cómo es la norma problematiza la cuestión de la forma de la misma, y la pregunta de qué contiene 
suscita el problema de su materia o contenido y simultáneamente el de la bondad o justicia de aquéllas.

Aunque es importante verificar todas y cada una de estas cuestiones y su resolución explícita, en este momento no vamos a ocuparnos de todas ellas, sino sólo de aquellas sobre las que ha incidido la concepción intelectualista y voluntarista de la norma y las demás concepciones complementarias posibles. Los problemas que han planteado, y resuelto a su manera, las concepciones indicadas son el por qué, el cómo y el qué de las normas o leyes, esto es los relativos a las cuestiones de la motivación, la forma de ser, y el contenido de las normas. La concepción intelectualista y voluntarista y las demás complementarias adoptan una determinada postura respecto de estas tres cuestiones, lo que significa una determinada resolución de los tres problemas a que éstas dan lugar.

Las tres cuestiones problematizadas y resueltas por estas concep. ciones afectan a la norma de diferente manera. La motivación de una norma es siempre algo extrínseco a la propia norma constituida, ya que se refiere a lo que ha impulsado su creación. Cualesquiera que fuesen los motivos por los que se crea una norma, caen fuera del ser estricto de la norma, son simplemente los promotores de aquélla. Por el contrario, la forma y el contenido de una norma, esto es, su forma de ser y su contenido, son cuestiones referidas a la constitución misma de la norma y afectan a dos aspectos fundamentales internos de la misma.

En general, la norma se puede concebir de muy diversas maneras en función de los diversos puntos de vista que se adopten. La concep. ción intelectualista, la voluntarista y sus complementarias, representan posibles formas de entender las normas desde determinada perspectiva. Son las concepciones que se obtienen como consecuencia de considerar la forma, el contenido y la motivación desde el punto de vista de la razón y la voluntad y lo que éstas exigen o implican.

En realidad tales concepciones generales, en tanto son concepciones de la norma exclusivamente, se obtienen por las soluciones que desde esta perspectiva se dan respecto de los probiemas de su forma y contenido, que son los aspectos que afectan al ser interno de la norma. No es necesaria la consideración de los motivos ni pronunciarse sobre este aspecto para definir teóricamente las diversas 
concepciones; pues, como ya hemos dicho, este aspecto es externo a la norma misma.

Por nuestra parte en la formulación teórica de las diferentes posturas que siguen, sólo aludiremos a la motivación en el caso de la postura intelectualista y de la voluntarista por las razones siguientes: la escuela franciscana históricamente es la que ha formulado con más rigor la postura voluntarista legal y llegó a ella precisamente a partir de la consideración de la necesidad o libertad en la creación de la norma. La postura intelectualista servirá para situar el extremo opuesto y contrapunto de la anterior posición. Y con ellas la problemática y resolución queda suficientemente planteada y esclarecida, sin necesidad de repetirla en las demás posturas.

En resumen, los problemas que se discuten respecto a la norma, desde una perspectiva de la razón y de la voluntad, son los tres indicados: por qué se crea una ley o norma, cómo es la norma creada y qué es lo que contiene. Lo concepción voluntarista de la norma define su postura respecto de cada uno de estos puntos de forma unilateral, pronunciándose por la voluntad y libertad en la génesis y formación de la ley. Supone que la creación de una norma es siempre el resultado de un acto de libertad del legislador; ninguna ley es necesaria en sí misma, depende sólo de la libertad de creación. Asimismo la norma misma formalmente consiste en un mandamiento, mandato, o precepto de la voluntad del legislador. La norma no consiste en el mandar como acto de voluntad, sino en el mandato, producto de un acto de voluntad. $\mathrm{Y}$ en tercer lugar el contenido del mandamiento, precepto o mandato, no sólo es lo querido por la voluntad del legislador y determinado por su libertad, sino que, por el hecho mismo de estar determinado y querido por la voluntad libre del legislador, es siempre y necesariamente algo bueno y justo sin que pueda ser de otra forma:

En cambio, la concepción intelectualista de la norma se pronuncia uniforme y unilateralmente por el otro extremo del binomio razónvoluntad, esto es, por la razón. En consecuencia la norma formalmente consiste en una exigencia racional - una ordenación $o$ imperativo de la razon - cuyo contenido es algo determinado, bueno y justo por sf mismo y conocido por la razón y la creación del ordenamiento, la normativa, viene exigida por necesidad racional, no está decidida por la libre voluntad del legislador. 
Es preciso recalcar que tanto la concepción voluntarista como la intelectualista de la ley asumen posiciones unilaterales y exclusivistas respecto de los problemas. Así, la concepción intelectualista de la norma considera que la ley es algo exclusivamente racional y desde esta teoria sólo se podrá calificar de intelectualista aquella ley que en sí misma esta constituida totalmente por la razón, es un producto que procede únicamente de la razón del legislador y lo que ésta im. plica. Paralelamente según la concepción voluntarista sólo se puede calificar del tal aquella ley cuyo ser está formado integramente por contenidos de voluntad, producto exclusivo de la voluntad del legislador y lo que ésta implica.

En consecuencia es necesario, pero no es suficiente, el hecho de que una norma esté formada por algún contenido de razón en su ser para poder clasificarla bajo el esquema intelectualista. Paralela. mente tampoco basta que un contenido de voluntad forme parte de una norma, para poder enmarcarla dentro de la concepción volun. tarista. Por el contrario, basta que cualquier contenido de voluntad forme parte del ser de una norma para poder afirmar que no es intelectualista y asimismo es suficiente que cualquier contenido de razón forme parte de una norma para poder afirmar que no se puede situar en el esquema voluntarista ${ }^{3}$.

${ }^{3} \mathrm{Es}$ corriente aceptar la tesis de que la concepción intelectualista y voluntarista de la ley significa simplemente una primacía del intelecto sobre la voluntad y al revés. H. Rommen en Derecho natural, Ius. Méjico. 1950, 142-3 dice: "Hemos demostrado ya, en páginas anteriores que en el dominio de la filosofía moral, la tesis de la superioridad de la voluntad sobre la inteligencia, conducía y debía conducir, más allá de Duns Scoto, a Ockam, al positivismo moral más completo...". "De lo dicho resulta que la doctrina de la superioridad de la inteligencia sobre la voluntad en Dios como en el hombre es la condición de la posibilidad de una ley moral natural, y por consiguiente de un derecho natural".

Creemos que lo que unánimemente se acepta como constitutivo del voluntarismo cn la concepción de la ley, esto es, que las cosas son buenas o malas porque están mandadas o prohibidas implica no una primacia de la voluntad en el sentido de que aquella pueda decidir independientemente de la razón sino una exclusión de la razón y consiguientemente que la voluntad supla su función. Pues si la voluntad actuara simplemente con independencia de la razón en la ley, lo único que se podría conseguir es que se mandara una cosa mala o buena en sí misma según decidiera lo que quicre mandar la voluntad, pero no que la hiciera buena o mala, por mandarla. Por tanto, ni la primacía de la voluntad implica ya un 
Por otro lado, puesto que estas concepciones representan la posición teórica que se adopta como consecuencia de considerar la norma desde la perspectiva de la razón y de la voluntad y como solución al problema que plantea esta consideración, esto es, el de saber en qué medicla los contenidos de razion y/o de voluntad forman parte cle la norma, es necesario discutir la misión que objetivamente le corresponde desempeñar a la razón y a la voluntad en el ámbito práctico en general y en particular en el ámbito legislativo. Es préciso consiclerar primero la función de la razón y de la voluntad en cl ámbito práctico general, porque las funciones que se les han de asignar en el ímbito legislativo dependen de las atribuidas en el primer ámbito. Una ver. eludidas estas bases, de ellas y según los resultados obtenidos, se podrá entonces criticar las posturas ya definidas del intelectualismo y voluntarismo legal y formular con claridad las demás posturas y su correspondiente valoración.

No podemos entrar a discutir a fondo estos problemas en este momento porque tienen suficiente entidad como para dedicarles estudio aparte. Necesariamente tendremos que recurrir a suposiciones $y$, en consecuencia, a formular hipotéticamente las bases de la discusión posterior. $\mathrm{Si}$, como es corriente, aceptamos que en el ámbito gencral prictico la razón tiene que desempeñar una doble función, que es, en primer lugar la de proyectar los actos realizables y en segundo lugar la de valorar tales actos desde el punto de vista de su bondad o maldad, o de su justicia o injusticia, y si aceptamos que cn el desempeño de esta función valorativa la razón no crea, sino simplemente descubre la bondad o maldad de los actos de acuerdo con lo que estos objetivamente son e independientemente de que la voluntad se proponga o no realizarlos; y si aceptamos igualmente que la misión de la voluntad es meramente realizadora de lo previamente proyectado y valorado por la razón, pero, en tanto es libre, puede decidirse por realizar cualesquiera actos propuestos, independien-

voluntarismo en la ley, ni es necesario tampoco una primacia de la inteligencia para explicar la ley natural y etema; como veremos la pucde explicar perfectamente una concepción de la ley tal que atribuya a la inteligencia y a la voluntacl el papel que le corresponda sin primacía de la una sobre la otra. 
temente de su bondad o malicia apreciada por la razón, entonces pre. suponemos en particular:

19) Que corresponde única y exclusivamente a la razón desempeñar la función valorativa; que la razón práctica en su función valorativa está condicionada o determinada por la objetividad de los actos o proyectos de actos realizados o por realizar; 29) Que todos los actos de querer, de preferir, y de elegir y de realizar, pertenecen exclusivamente a la voluntad libre. Se supone también que el ejercicio de la voluntad se halla condicionado por la previa formación de uno o más proyectos elaborados por la razón, pero igualmente se supone que la voluntad no se halla determinada de ninguna manera por la razón, ni por nada extrínseco a la propia voluntad, sino que se autodetermina intrínsecamente a causa de la libertad.

De acuerdo con esto, en el ámbito legislativo o de formación de la norma, ha de ocurrir lo siguiente. A la razón práctica corresponde exclusivamente la misión de formular proyectos de norma, es decir, aquélla propone los actos que van a ser objeto de mandato o de prohibición en vista de algún fin. $\mathrm{Y}$ asimismo corresponde exclusivamente a la razón el juicio o valoración de tales actos sobre la adecuación o no adecuación al fin propuesto y sobre la bondad, maldad, justicia o injusticia de los mismos. Pero corresponde a la voluntad del legislador decidir acerca de la creación, o no, de la norma proyectada, y es la voluntad legislativa también la que impone la exigencia de que tales actos se cumplan. Estas funciones son intransferibles, ni la razón es idónea para ninguna forma de querer, ya sea querer cle uno mismo y para sí mismo o querer en tanto imposición u orden o mandato a los demás; ni la voluntad es capaz de apreciar y juzgar sobre la adecuación, bondad, maldad, justicia o injusticia, de las acciones.

Si analizamos una norma, encontraremos que comprende al menos un mandato, csto es, un precepto, o imperativo, o bien, una cxigencia, o deber. Pero comprende también y se puede distinguir del elemento anterior un contenido, pues no existe mandato sin un contenido. Siempre se halla mandato o mandamiento de algo, un precepto o imperativo de hacer o no hacer, una exigencia o deber de adoptar una determinada conducta. En definitiva, en toda norma de conducta se puede distinguir ci mandato y lo mandado, el precepto y lo preceptuado, el deber y lo lebido, esto es, la forma de la norma 
y el contenido de la misma. Claro está que se trata de una distinción hecha por la razón, pues en la realidad los dos elementos están íntima mente unidos, pues no puede darse un mandato sin contenido, un mandato $\sin$ lo mandado y viceversa.

Desde estas distinciones se puede plantear el problema de si es la voluntad o la razón, o mejor aún para evitar una interpretación psicologista, si son contenidos de voluntad o de razón los que constituyen el mandato -o el precepto, o el imperativo, o el deber- por una parte y por otra si son contenidos de voluntad o de razón los que constituyen el contenido del mandato o precepto -lo mandado, lo preceptuado, etc. - y la valoración del mismo. En otras palabras se plantea el problema concreto de si el mandamiento o precepto o deber es un contenido de razón o de voluntad y asimismo si el con. tenido o materia del mandamiento y su valoración es un contenido, producido por la razión o por la voluntad.

Desde este punto de vista son posibles cuatro soluciones en un platno general, puramente teórico. Son las cuatro posibles combinaciones que resultan de considerar estos dos elementos que hemos denominado materia y forma o contenido y precepto bajo la doble posibilidad de que cada uno sea entendido como producto de la razón o de la voluntad, esto es como contenido de razón o de voluntad.

Y dada esta perspectiva problemática de consideración es lógico que dentro de las soluciones posibles dos de ellas coincidan con las que definen la concepción intelectualista y voluntarista de la norma ya formuladas anteriormente junto a las otras dos posibles y que todavía no lo han sido. Para ofrecer el panorama completo a continuación enunciaremos brevemente todas las posibles concepciones, que son las posibles soluciones al problema planteado.

Una primera concepción posible es la de cntender que es un contenido de razón lo que constituye el mandato o mandamiento, cl precepto o imperativo, el deber o exigencia. $Y$ que asimismo es un contenido de razón el que determina el contenido de este mandato, imperativo o deber, y la calificación del mismo. Estamos ante la concepción intelectualista de la norma, postura unilateral y excluyente. Sc considera que la norma está formada exclusivamente por contenidos racionales y no contiene absolutamente ningún conte. nido de voluntad.

Una segunda concepción posible es la de entender que es un 
contenido de voluntad to que constituye el mandato o mandamiento, el precepto o imperativo, el deber o exigencia. $Y$ que asimismo es un contenido de voluntad el que determina el contenido de este mandato, imperativo o deber y la calificación del mismo. Estamos ante la concepción voluntarista de la norma postura unilateral y excluyente. Se considera que la norma está formada exclusivamente por contenidos volitivos y no contienc absolutamente ningún contenido de razón.

Una tercera concepción teóricamente posible de la norma es la que considera que es un contenido de razón el que constituye el mandato o mandamiento, el precepto o imperativo, el deber o exigencia, esto es la forma de la ley. $\mathrm{Y}$ que es un contenido de voluntad el que determina el contenido de este mandato, imperativo o deber y la calificación del mismo. Estamos ante una postura bilateral no excluyente. La norma está formada por contenidos de razón y de voluntad los cuales afectan a determinados aspectos de la misma.

Una cuarta concepción teóricamente posible de la norma es la que considera que es un contenido de voluntad lo que constituye el mandato o mandamiento, el precepto o imperativo, la exigencia o deber, esto es la forma de la ley. $Y$ que es un contenido de razón el que determina el contenido de este mandato, imperativo o deber y la calificación del mismo. Estamos ante otra postura bilateral no excluyente. La norma está también formada por contenidos de razón y de voluntad pero afectan de otra manera a los mismos aspectos de la ley. Y ya no caben más posturas.

\section{CRITIGA DE LAS CONGE P C ION E S}

Si aceptamos que en el ámbito legislativo la función objetiva que tiene que desempeñar la razón y la voluntad en la formación de la norma de conducta son las indicadas anteriormente, entonces, desde esta base de presupuestos y de acuerdo con ellos, se podrá despejar rápidamente el problema de si el mandato o precepto de una norma es un contenido de razón o de voluntad y el de si el contenido del mandato o materia del precepto y su valoración es un contenido de razón o de voluntad. $Y$ en general se podrá pasar a criticar y apreciar cada una de las distintas concepciones de la norma como producto de razón $y / 0$ de voluntad, indicando qué concepciones son 
conformes o disconformes, adecuadas o inadecuadas y la medida en que lo son, con lo que objetivamente le correspondería ser, si se tiene en cuenta el papel de la razón y de la voluntad en la formación de la ley.

$\mathrm{Si}$, de acuerdo con las bases sentadas, es la voluntad del legislador a la que objetivamente corresponde mandar, imperar o preceptuar, entonces el mandato, precepto o imperativo como elemento formal constitutivo de la norma, ha de ser un contenido de la voluntad, producto de la voluntad del legislador y no de la razón, pues la razón no es apta para mandar y un contenido de razón no puede constituir el mandato. $Y$ si la razón del legislador es a la que objetivamente corresponde determinar el contenido del mandato y efectuar su valoración, entonces lo determinado y valorado como contenido - materia del precepto ha de ser un contenido de razón, producto de la razón del legislador y no de la voluntad, pues la voluntad no es apta para determinar contenidos de preceptos y menos aún para apreciar su bondad o maldad, justicia o injusticia.

Bajo estos supuestos la concepción intelectualista de la norma resulta ser una concepción inadecuada. Efectivamente se entiende que la norma está total y exclusivamente constituida por contenidos de razón sin ningún contenido de voluntad, y por tanto que es producto exclusivo de la razón. Tanto el mandato o precepto como el contenido del mandato y su valoración son contenidos de razón. Según el criterio sentado, lo primero es erróneo y lo segundo acertado, pues el mandato o precepto no es producto y contenido de razón sino de voluntad.

Por otro lado mirando a la causa que produce la norma, la concepción intelectualista al considerar a aquélla como producto exclusivo de la razón, supone excluir totalmente la participación de la voluntad en la formación de la norma. $Y$ presupone no sólo que la razón ha desempeñado su función propia, cual es la de determinar y valorar el contenido del mandato, sino que ha suplantado la función de la voluntad cual es la de preceptuar o mandar y ha desempeñado impropiamente esta función puesto que la razón no es apta para mandar.

Esta concepción considerada globalmente; sin duda es errónea en el plano teórico según los supuestos indicados, pero en el plano práctico no puede producir malas consecuencias, ya que según ella la 
razón y los contenidos de razón siguen desempeñando y ocupando la función y lugar que les corresponde. Esta concepción defiende que la justicia o injusticia de la norma o bondad o maldad del contenido de la misma, vienen dadas por la razón, la cual, según su función axiológica, permite valorar de justo o injusto el contenido de la norma, según los actos que objetivamente estén mandados o prohibidos.

En las mismas condiciones la concepción voluntarista de la norma resulta ser también inadecuada e incorrecta. Efectivamente según esta concepción se entiende que la norma está, total y exclusivamente constituida por contenidos de voluntad, sin ningún contenido de razón, y que la norma es producto exclusivo de la voluntad. De acuerdo con esta concepción, pues tanto el mandato o precepto, como el contenido del mandato y su valoración son contenidos de voluntad. Según el criterio objetivo aceptado, lo primero es acertado y lo segundo erróneo, pues el contenido del mandato y su valoración no son ni pueden ser producto de la voluntad, sino de la razón.

Por otro lado, contemplando la causa que produce la norma, la la concepción voluntarista al considerar que la norma es un producto exclusivo de la voluntad, excluye totalmente la participación de la razón y sus contenidos en la formación y constitución de la norma. Y presupone no sólo que la voluntad ha desempeñado la función propia que le correspondía desempeñar, cual es la de mandar $\circ$ preceptuar, sino que ha suplantado las funciones propias de la razón, como son la de determinar el contenido del precepto o mandato, y la de efectuar según su proceder la valoración del mismo. Pero la voluntad es incapaz de determinar el contenido de un mandato y más todavía de juzgar sobre la justicia o injusticia del mismo, y por tanto ha desempeñado una función impropia, que no podía ni le correspondía realizar.

Esta concepción en conjunto es también errónea, por más que tenga un acierto parcial en lo referente a que el mandato o precepto es un contenido de voluntad. Pero de aceptarse, pueden derivarse consecuencias graves en el plano práctico, porque según ella la valoración del contenido del precepto depende de la voluntad, está en función de la misma. Algo es bueno simplemente porque está querido positivamente por la voluntad del legislador, esto es, porque está mandado. $Y$ algo es malo simplemente porque está querido negati 
vamente por la voluntad del legislador, esto es, porque estí prohibido.

Esto significa que la bondad o maldad objetivas del contenido de un mandato o precepto no existe. Un mismo contenido de un mandato puede ser bueno o malo, justo o injusto, según se mande o se prohíba, En tal caso no se puede nunca discutir sobre la justicia o injusticia de la norma, pues la norma y su contenido por el sólo hecho de existir, determina siempre lo justo y lo injusto, sin poder apelar a ninguna otra realidad extraordinaria, para apreciar su justicia o injusticia.

En igualdad de circunstancias, la tercera concepción posible de la norma expuesta anteriormente es también inadecuada $e$ incorrecta, $y$ la más inadecuada. Efectivamente, según esta concepción, se entiende que la norma está constituida por contenidos de razón y de voluntad, y por tanto se considera que la norma es producto de la razón y de la voluntad. Pero de acuerdo con esta concepción el mandato o precepto es un contenido de razón, y el contenido del mandato y su valoración es un contenido de la voluntad. Según el criterio objetivo aceptado es tan erróneo lo primero como lo segundo, pues el mandato o precepto no es ni puede ser contenido de la razón, sino de la voluntad, y el contenido del mandato o precepto y su valoración no son ni pueden ser contenidos de la voluntad, sino de la razón.

Contemplando la causa que produce la norma, esta concepción, al considerar que la norma es un producto de la razón y de la voluntad significa que participan ambas facultades en la creación de la ley y por tanto no excluye a ninguna. Pero presupone que la razón desempeña la función que objetivamente le corresponde a la voluntad y que la voluntad realiza la misión que le toca a la razón, por lo que tanto la razón como la voluntad intervienen en la formación de la ley en funciones impropias, para las que no están capacitadas.

Esta concepción es errónea en su conjunto y en todas sus partes de acuerdo con los supuestos indicados. En realidad suma los errores de la concepción intelectualista y voluntarista. Suma también los inconvenientes prácticos de las dos, que son los que se derivan de la concepción voluntarista, pues la concepción intelectualista no es peligrosa en este terreno, tal como hemos indicado anteriormente. Consecuentemente, según esta tercera concepción, la justicia o injusticia no existe objetivamente, sigue siendo función de la voluntad y se 
defiende en último término, que todas las normas o contenido de las normas son justos o buenos o injustos o malos por el mismo hecho de estar mandados o prohibidos.

Bajo los supuestos indicados la única concepción adecuada o correcta de la norma es la que hemos expuesto como cuarta posibilidad teórica de concebir una norma. Según esta concepción, la norma está compuesta de contenidos de razón y de voluntad, y por tanto se considera que la norma es producto de la razón y de la voluntad del legislados. Pero a diferencia de la concepción anterior, los contenidos de razón y de voluntad están integrados en la norma según el lugar que objetivamente les corresponde: se supone que el mandato o precepto es o consiste en un contenido de voluntad y que el contenido del mandato y su valoración consiste en contenidos de razón. Según el criterio objetivo aceptado, es tan acertado lo primero como lo segundo, pues el mandato sólo puede ser contenido de voluntad tal como aqui se propone y el contenido del mandato o precepto y su valoración sólo puede ser contenido de razón tal como aquí se defiende.

Por otro lado, contemplando la causa que produce la norma, esta concepción considera que la norma es un producto conjunto de la razón y de la voluntad, ambas facultades participan en la confección de la ley, por esto la norma está constituida por los productos o con. tenidos de aquellas facultades. Pero, a diferencia de la anterior concepción, presupone además que en la elaboración de la norma, la voluntad desempeña la función que le corresponde y lo mismo le ocurre a la razón, por lo que tanto una como otra intervienen en la creación de la norma según sus propias funciones, para las que están catpacitadas.

Esta conccpción es la única verdadera en su conjunto y en todas sus partes, si se aceptan los presupuestos en que se funda. Muy sintéticamente recordados son: que la razón es la única capaz de determinar y valorar los contenidos de los preceptos y la voluntad es la única capaz de preceptuar o mandar. 'También esta concepción, lo mismo que la intelectualista defiende que existe la justicia o injusticia de la norma, pues el contenido de los preceptos o prohibiciones, es algo objetivo que aprecia la razón según sea el contenido mismo, de ninguna manera la bondad o malicia depende de ser objeto de mandato o prohibición. Esto es, la justicia no depende en absoluto de la vo- 
luntad del legislador, sino que es completa y absolutamente independiente. Por esto pucde ocurrir por una parte, que el legislador mande realizar algo que objetivamente sea malo, o bien algo que sea objetivamente bueno; y por otra parte puede igualmente ocurrir que el legislador prohiba realizar como contenido del mandato algo que objetivamente, sea malo o injusto o bien algo que sea bueno y justo. En último término, esta concepción defiende la posibilidad de valorar las normas, éstas pueden calificarse de justas o injustas y abre camino a una crítica para mejorar o anular la norma.

III. DIOSCREA D O X I L E G ISLA D O K

Una vez esclarecido lo que entendernos por concepción intelectualista y voluntarista de la ley y además otros modos posibles y fundamentales de concebirla. tenemos que indagar qué posibilidades y sentido pueden asumir estas posiciones en el caso especial de la ley eterna.

Creemos preciso observar que en la relación Dios-mundo hay que distinguir bien dos planos, que son el de la creación y el de la legislación; es frecuente considerarlos globalmente sin hacer un preciso cliscernimiento y esto enturbia y desenfoca el planteamiento de esta cuestión en la ley eterna.

Según la doctrina escolástica y neoescolástica, Dios es creador y Dios es además, legislador de los seres creados. La ley cterna supone necesariamente la creación de los seres, que es previa si no en el aspecto temporal, al menos en el aspecto lógico. Si queremos evitar lagunas e imprecisiones, hay que advertir que se puede plantear el problema del intelectualismo y del voluntarismo en ambos niveles, esto es, en el plano de la creación y en el plano de la legislación. Nos ocuparemos brevemente de la primera cuestión para evitar confusiones en la segunda.

Previamente queremos hacer una observación de teologia, que aunque sabida, es necesario recordar ahora. La distinción entre razón y voluntad divina de la que en lo sucesivo vamos a hacer frecuente uso, supone una concepción antropomórfica de la realidad divina, que como acto puro, no se presta a una distinción real. Es el resultado de la proyección de facultades y categorias propiamente humanas al plano de la divinidad. Sin embargo, sirven para una mejor 
comprensión, según las posibilidades humanas, del inefable Ser divino4.

En el plano ontológico, o aspecto de la creación, simplemente afirmaremos que no se puede mantener una postura intelectualista porque resulta contradictoria y falsa. Supone que Dios ha creado un mundo ontológicamente bueno porque las ideas de las cosas a crear eran buenas y existian por sí mismas, en vista de lo cual, Dios creó el mundo movido por exigencias de su razón; por necesidad, pues, no libremente. Esto significa en definitiva que la razón divina y sus exigencias fueron la causa total y única de la creación.

No se pueden sustentar estas ideas desde la teologia natural y escolástica, pues sólo Dios aparece como ser necesario, existente por sí mismo, bueno, etc. Dios se nos muestra como ser eterno y así en principio no existia más que Dios. Excepto Dios antes de la crea. ción no cabía cosa alguna con entidad propia. Ideas buenas por sí mismas con entidad propia e independiente de Dios, a modo de ideas platónicas, no podían existir si no queremos contradecir la idea y la realidad divina con sus atributos. En todo caso, tenían que ser ideas de Dios, a modo de causas ejemplares existentes en su mente que en definitiva no eran algo distinto y mucho menos independiente de Dios. Por otra parte, tampoco se puede admitir que Dios tuviera necesidad absoluta de crear, de modo que se excluya su libertad.

Por otro lado tenemos que afirmar que tampoco se puede admitir un voluntarismo puro en el nivel de la creación, según la teología católica, porque esto importaria afirmar no sólo que Dios ha creado el universo por su querer libérrimo, sino con querer irracional, sin

"Agustín de Asís, a firma: "Nituralmente que el planteamiento de que sta primero, si la razón o la voluntad, es imposible clesde un punto de vista estrictamente ontológico. pues siendo Dios actus purtus, no puede haber en El distinción entre la razón y la voluntad. Tampoco es posible este planteamiento desde un punto de vista lógico, ya que también al ser actus purus, por la perfección que ello implica, la razón se manifiesta al mismo tiempo como voluntad, y viceversa, sin que haya lugar al espacio de indeterminación que supondria csta no identidad. Solamente cabe plantearse esta distinción, como muy bien indica nuestro maestro Elías de Tejada, a efectos puramente del conocimiento humano y para aplicaciones también meramente humanas, aunque estén preñadas de sentido", Manual de Derecho natural. Urania. Granada. 1963, 537. 
establecer un orcien intrínscco en las cosas, ni fijar finalidad alguna”. El voluntarismo en este plano, supone mantener que la libre voluntad de Dios es la causa total y excluyente de la creación. Esto contradice la realidad del mundo. Sin una ordenación racional que organizara lat estructura de cada ser, sólo podría existir un mundo caótico.

Una explicación suficiente parece ser que Dios ha creado el mundo por decisión de su libre voluntad, sin necesidad, pero racionalmente imprimicndo un orden constitutivo en los seres sin el cual no podrian cxistir ni subsistir el ser y mundo actuales, sino un caos.

\section{CONCEPGIONES DE LA NOR M A}

$$
\text { Y L E E I }
$$

Esbozada la cuestión anterior, podemos ya plantear el problema con más amplitud en el plano de Dios Legislador, es decir, en la ley eterna. Consiste en investigar cuáles son los modos posibles bajo los cuales podemos concebir la ley eterna y, en especial, si cabe entenderla de forma intelectualista y voluntarista.

La ley eterna -como ya hemos adelantado en parte- presupone la creación y creación racional por parte de Dios y consecuentemente la existencia de un universo intrínsecamente ordenado, o bien la exis. tencia de un orden general de todos los seres del universo y un orden particular para cada uno de ellos, mundo ordenado y orden del mundo son dos aspectos de una misma cosa, puesto que en las condiciones actuales el ser implica el orden y el orden se da en el ser6.

La ley eterna - conforme se viene entendiendo desde siglos- consiste en que Dios creador quiere que se conserve y perpetúe la creación con su orden intrínseco y, en consecuencia, exige - ciertamente de

"Corts Grau indica: "Creación y ordenación se compenetran. Dios al concebir la esencia de las criaturas, les asigna un fin y una dirección...", Curso de Derecho natural. Editora Nacional. Madrid. 1964, 244.

${ }^{\circ}$ Agustín de Asís afirma al respecto: "En definitiva orden y ser son dos términos coextensivos, es decir, en la medida que algo es, es también orden; y todo orden es ser, de forma que, si el ser es trascendente esta primera noción de orden trasciende también a todos los seres particulares, como hemos sénalado más arriba", op. cit., 62.

Puy Muñoz, por su parte, pone de manifiesto la estrecha relación existente entre la creación del mundo por parte de Dios y la legislación a que lo 
clistinto modo a los diversos seres- que se respete el orden establecido por todos y cada uno de ellos?.

Dios, quiere pues, que cada criatura actúe de acuerdo con su propio ser y orden interno. Esto importa dos cosas que es necesario destacar: por una parte Dios exige, y de diversa manera según la categoria esencial de los seres, por otra parte, aquello que Dios exige a cada ser es algo determinado y determinable objetivamente. Lo que Dios exige a cada ser es su propio bien, pues el bien consiste precisamente que cada cosa se mueva o actúe de acuerdo con su ser y orden interno. El ser que actúa de acuerdo consigo mismo, ajustándose a su orden constitutivo, actúa bien, ontológicamente bien, tiende a perfeccionarse, a realizar su plenitud ontológica. En particular el bien ontológico del hombre -que por ser racional libremente realizable es además bien moral- consiste en actuar de acuerdo con su modo de ser y así serán actos buenos o malos para él, Ios que la razón indica que están conformes o disconformes con su ser, o naturaleza racional.

La bondad y maldad objetiva depencle del ser y por tanto de la creación. El ser no es nada antes de la creación, de modo que en este momento no se puede hablar tampoco de actos que sean buenos o malos en sí mismos. Supuesta la creación, algunas acciones son

somete: "La idea de la creación, en efecto, implica la siguiente tesis: por ser Dios creador de las cosas, es su conservador y gobernante. Pero no hay artifice que no tonga en su mente el plan de la cosa que ha hecho, antes $y$ despućs de haccrla. Igualmente no hay gobernante que no tenga en su mente el plan de las cosas que manda hacer, antes y después de mandarlas. Semejantemente así como la razón de la divina sabiduría, en cuanto que todas las cosas han sido creadas por ella, tienen carácter de arte, de ejemplar, de idea de las mismas, así también esta misma razón di la sabiduría divina, en cuanto nueve todas las cosas hacia su debido, fin. tiente carácter analógico de ley". Lecciones de Derecho natural. Porto y Cía. Editores. Santiago de Compostela. 1970, 296.

"Laño Peña de acuerdo con la tradición define así la ley eterna: "Es a mismo orden universal concebido por Dios e impuesto a todos los seres", Derecho natural. Librería La homiga. Barcelona. 1961, 261. A. F. Utz, afirma: "No es la creación misma de una determinada finalidad la que constituye ya la ley eterna, pues esto sería mera casualidad, sino la disposición que acompaña a este acto creador, que exige el respeto del orden con su finalidad y prohíbe su atropello", op. cit., 86. 
buenas o malas en sí mismas por la relación que guardan con el ser. Son buenas si y porque están conformes, y malas si y porque están disconformes con el orden del ser.

Por la creación se predetermina lo que va a ser bueno o malo para cada ser, lo cual no podrá variar, si no varía el ser. Dios creó Jibremente los seres, cosa que podía no hacer, y además con la creación predeterminó lo que iba a ser bueno o malo para cada uno de ellos. Una rez creados los seres con unas características y orden interno, necesariamente existen acciones buenas y malas en sí mismas - Caso de las acciones humanas - la bondad o maldad es determinable objetivamente por relación al ser y naturalmente es cognoscible por la razón tanto divina como humana. Ni siquiera Dios puede alterar lo que es bueno o malo para un ser, si no modifica previamente la estructura de este ser.

Por otra parte, ya sabemos que la concepción voluntarista aplicada a la ley eterna implicaría creer que todo el ser de ésta lo constituye la voluntad divina, de modo que habría que entender que Dios no sólo manda a todas las criaturas - por medio del querer de su voluntad-sino que su voluntad determina también libremente lo que es bueno y malo para ellas y es objeto de su mandato.

Un elemento o requisito indispensable de la concepción voluntarista de toda ley -y por tanto también de la ley eterna- es que lo que se mande se considere bueno o malo simplemente porque está mandado. Esto supone negar - ya lo hemos adelantado- la existencia de actos buenos y malos en sí mismos, por relación al ser. Pues si un acto es bueno simplemente porque se manda, y malo porque se prohíbe, un mismo acto puede ser sucesivamente bueno o malo según se mande o prohíba.

De momento se puede ya concluir que no cabe un entendimiento voluntarista de la ley eterna. Pues, aún prescindiendo del problema de si Dios manda por la voluntad -elemento necesario de la concepción voluntarista- o por la razón, ocurre que lo que Dios manda a los seres no es cualquier cosa determinada por pura voluntad divina -el otro elemento indispensable de aquella concepción- sino que manda que se observe y perpetúe el orden establecido, lo cual es exigirles su propio bien.

En definitiva, después de la creación se pueden imaginar dos supuestos, respecto de lo que Dios manda o exige a las criaturas. Uno 
es que quiera y mande que se conserve el orden estableciclo en y para los seres, es decir, que dirijan sus movimientos respetando el orden de su ser. En este caso resulta que Dios tiene en cuenta el ser y orden intrinseco y exige que se haga lo que objetivamente es bueno y que se evite lo que objetivamente es malo. Este es precisamentc el caso de la ley eterna $\mathrm{y}$ así es imposible una concepción voluntaristas.

Un segundo supuesto sería - como defiende Duns Escoto y Ockamque después de la creación lo que Dios manclara a las criaturas sea bucno porque está y mientras estuviera mandado y malo porque estí y mientras estuviera prohibido y asi, si Dios quisiera, lo que ahora es bueno lo podría transformar en malo y al revés con sólo cambiar de querer. Esto implicaría que Dios manda algo independientemente del ser, o como si no existiera un orden en la creación. Desconectado así el contenido del mandato divino del ser y su orden intrínseco es imposible concebir la ley eterna, que precisamente exige conservar estc orden y prohíbe perturbarlo. En tal supuesto se podrát concebir un Dios eterno que manda lo que quiere sin consideración al ser, pero no se podrá concebir la ley eterna en la cual bios no manda lo que quiere.

Tampoco es conciliable con la noción de ley eterna, cualquier otra concepción de la ley que también asigne a la voluntad del legis. lador la función de determinar como bueno o malo, lo que se manda. En este supuesto se encuentra aquella concepción general de la ley que entiende que es la razón la que propiamente manda y la voluntad la que determina la justicia, o injusticia de la ley. Históricamente no se ha sustentado tal postura, aplicando el esquema al plano divino,

'Es más - y este es un aspecto que ahora sólo queremos apuntar- supucsta la creación, la ley eterna es necesaria, no libre. Libre fuc la creación. De modo que no soblo Dios no manda lo que quiere sino que necesariamente tiene que mandar algunas cosas y prohibir otras que son las que son esencialmente bucnas o malas por estar conformes o disconformes con lo esencial al ser de cada critura.

${ }^{\circ}$ Welzel dice acertadamente de Duns Scoto: "no conoce por ello ya una ley eterna. Eterna no es la ley, eterno es el legislador. No conoce tampoco - prescindiendo del amor a Dios- ninguna acción buena o mala en sí, es decir ninguna acción cuya materia sca buena o mala per se et sua natura..."; y respecto a Ockam: "Para Ockam, no hay ya en absoluto una ley esencialmente buena, sino sólo un legislador escncialmente bueno", op. cit., 94 y 115 . 
pues la escuela franciscana en general ha creido que el acto de mandar procede naturalmente de la voluntad.

Acabamos de examinar las concepciones bajo las cuales no cabe enfocar la ley eterna, si no queremos destruir su noción. Seguidamente pasamos a considerar los esquemas que hacen posible su comprensión.

Puede explicar la ley eterna toda concepción de la ley que implique que se mande o se prohíba lo que por sí mismo es bueno o malo independientemente de cualquier voluntad. Están en estas condiciones las concepción intelectualista y la que hemos denominado concepción adecuada de la ley.

La concepción intelectualista supone imaginarse que Dios manda a todos los seres conservar el orden, es decir, lo que objetivamente es bueno para ellos, si bien se cree que este mandato procede precisa. mente de la razón divina.

La concepción adecuada de la ley, aplicada a la ley eterna implica considerar que Dios manda por medio de la voluntad -y no por medio de la razón-que las criaturas respeten el orden de la creación, esto es, lo que objetivamente $u$ ontológicamente es bueno para ellas.

Ambas concepciones permiten interpretar la ley eterna. Pues lo que Dios quiere y manda a las criaturas -mande por la razón o por la voluntad- es su propio bien y les prohíbe realizar su propio mal al exigirles respetar el orden en sus actuaciones o movimientos.

El problema subsiguiente es saber cuál de las dos concepciones -la intelectualista o la adecuada- puede sernos válida para un perfecto entendimiento de la ley eterna. Pero no entra dentro de nuestro propósito resolver ahora esta cuestión.

V. P R O BLEMA DE LA DEF I N I CION DE SAN AGUSTIN Y TEORIA DE DUNS SCOTO

Dspués de lograr el objetivo principal propuesto, secundariamente y de paso, queremos poner también de relieve que la definición de la ley eterna que dio San Agustín, recogida al principio de este trabajo, plantea precisamente el problema de si ha de ser entendida según la concepción intelectualista o la adecuada de la ley, pues las demás no son posibles.

Conviene repetir ahora que la ley eterna según San Agustín es la 
razón o la voluntad divina que manda conservar el orden natural y prohíbe perturbarlo. Si se entiende que es la razón divina la que manda conservar el orden natural, nos situamos bajo un entendimiento intelec. tualista de la ley eterna. Si entendemos que es la voluntad divina la que exige mantener este orden, debemos encajarla y calificarla según el esquema o concepción adecuada de las normas. Esta definición plantea precisamente el problema entre estas dos concepciones, pero no puede resolverse dentro de los límites de la definición, hay que acudir o otros pasajes del autor para intentar resolverlo. Queda absolutamente despejado que la disyuntiva que enuncia la definición de la ley eterna hecha por el Santo de Hipona no se plantea entre la posibilidad de una concepción intelectualista y la voluntarista, pues esta última no es posible.

Finalmente queremos también aludir brevemente a la postura total adoptada por Duns Scoto respecto de los problemas aquí tratados y aludir a la contraria. Históricamente la cuestión intelectualismo-voluntarismo dentro de la escuela franciscana se planteó como problema teológico, el de averiguar si existían o no límites en la libertad divina. La escuela franciscana reivindicó enérgicamente la ilimitación de la libertad divina, tanto en el plano de la creación como en el de la legislación, exceptuando sólo el orden lógico. Consecuentemente a esta postura Duns Scoto inició y defendió la teoría del voluntarismo legal y exageró el papel de la voluntad divina en el orden legislativo.

Ya en un plano general no referido a Dios, Duns Scoto defendió la inclependencia de la voluntad respecto de la razón. Esta no es la causa determinante de la voluntad, sino sólo una condición sin la cual no puede funcionar. Utilizó el simil del criado que ilumina razón- donde le indica el señor-voluntad decisoria libre. La vo. Iuntad es libre, si quiere algo, y lo que quiera, lo decide libremente con total independencia de que lo querido sea bueno o malo. Pero Duns Scoto no se detuvo aqui, respecto de Dios. Proclamó que Dios no sólo era absolutamente libre en el querer o no querer, sino que afirmó que lo que Dios quería era siempre bueno, y lo que Dios no quería, malo, precisamente por quererlo o no quererlo.

Esta doctrina teológica aplicada al plano de la legislación define la postura del voluntarismo legal. Dios es absolutamente libre de mandar o no mandar algo a sus criaturas, entre ellas al hombre. Y, en el supuesto de que decida darles una ley o norma, puede determinar 
el contenido que quiera, pues lo preceptuado, por serlo, será siempre lo bueno, y lo prohibido será siempre malo, simplemente por estar prohibido por Dios. Se ha pronunciado ya respecto del problema de la causa libre o necesaria de la norma y respecto del contenido de la misma. Por descontado ni se discute siquiera que el mandato mismo, lo que denominamos forma es también un contenido de voluntad y no de razón 10 .

Frente a estos tres extremos la postura intelectualista es la contraria. Dios necesariamente tiene que dar una ley a sus criaturas -ley eterna-. Dios manda lo que objetivamente es bueno y prohibe lo que objetivamente es malo, precisamente lo manda porque es bueno y lo prohíbe porque es malo. $\mathrm{Y}$ el mandato mismo es un contenido de rizón.

\section{CON CLUSIONES}

En resumen las conclusiones finales a que hemos llegado son que la la ley eterna no es susceptible de ser concebida en forma voluntarista, puesto que ello implica aceptar que la voluntad divina exige lo que la misma voluntad determina como bueno o malo para las criaturas y esto es distinto e incompatible con lo que se entiende, qué es la ley eterna.

Teóricamente al menos, cabe entender la ley eterna en forma intelectualista $o$ adecuada. Pues en ambos casos igualmente se presupone que lo que se manda es precisamente conservar el orden y evitar el desorden, lo cual constituye el bien de cada ser, si bien difieren en que según una, el mandato se verifica por la razón y según la otra por la voluntad. Cuál de las dos formas posibles sea la más acertada para captar mejor la realidad de la ley eterna, es un problema que

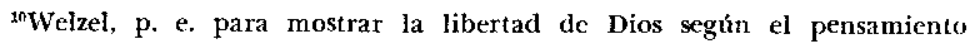
de Duns Scoto, trae a colación citas de este doctor referidas al plano ontológico y legal, sin advertir de ello: "Ia voluntad de Dios que quiere precisamente esto, y que lo quiere precisamente ahora, es la primera y directa causa, para lo cual no hay que buscar ninguna otra causa". "Todo lo que existe fuera de Dios es bueno, porque Dios así lo quiere, pero no al contrario, lo aprueba Dios porque es bueno". "Las leyes generales del obrar recto están fijadas por la voluntad divina, no por el intelecto divino, tal como éste precede a quélla. En dichas leyes, en efecto, no es posible encuadrar ninguna necesidad conceptual", op. cit., 89 y 91 . 
se suscita ahora, pero que no nos proponíamos resolver. Secundariamente creemos haber demostrado, además, que la definición de la ley eterna de San Agustín no permite plantear el problema de si mantuvo una concepción intelectualista o voluntarista de tal ley, sino que puede suscitar el problema entre la concepción intelectualista y la adecuada. 